\title{
Research, adult and further education and criticality: catalysing hope and dialogic caring
}

\section{Abstract Dr Vicky Duckworth and Dr Rob Smith}

This paper draws on a longitudinal UCU research project: FE in England - Transforming Lives and Communities to explore transformative learning within adult and further education and to argue for the place of research in affirming localised understandings of education that cut across the grain of contemporary educational reform. In the context of the dominance of a 'skills' discourse in further education in England and the flux of continual policy interventions, this research project focused on further education as 'differential space' (Lefebvre 1991) that is emancipatory for many learners at the local level. The research data illustrate that further education can be disruptive of the rigid linearity of the model of 'learning progression' at the heart of neoliberal models of education that assesses and sorts individuals according to a qualification/age matrix. Instead, it can offer organic tools for consciousness-raising (Freire 1995) and transformation (Mezirow 2000, Illeris 2013), acting as a hope catalyst for significant changes in learners' lives and teachers' practice (Duckworth 2013; Duckworth and Smith 2017).

To support the discussion, our paper draws on a range of learners and teachers' narratives to expand on the view of further and adult education as a space for the exploration of a curriculum informed by an ethic of what we term dialogic caring. We also develop a theoretical position that anchors research in learners and practitioners' experience as an empirical antidote to the simulations (Baudrillard 1994, Lefebvre 2004) conjured up by the decontextualised statistical data (such as PISA) that drive current policy-making. Through the use of the notion of transformative learning, we position critical pedagogy as working towards a model of education with social justice at its heart and against education structures that marginalise women, their families and communities. We also seek to actualise an affirmative research practice that foregrounds and connects with critical pedagogy at the local level as well as providing 
an understory for neoliberal 'grand narratives' of international competition and comparison.

\section{Introduction}

Literacy is crucial for promoting women's rights and for their empowerment (PantsRobinson, 2016). It plays a vital role for Lifelong Learning in the different ways that it fosters capacities, reduces vulnerabilities and improves the quality of life for women, their families and the wider community. Indeed, women are marginalised and often silenced if they are unable to access the powerful tools that literacy offers that can enable them to transform their lives (Duckworth, 2013; Duckworth \& Smith 2017).

\section{Positioning Literacy and Hope}

In the UK and internationally, the current discourse around literacy is driven by international surveys that have become increasingly important over the last twenty five years. Produced and promoted by a range of agencies including the Organisation for Economic Co-operation and Development (OECD), UNESCO and the European Union, national governments commit considerable funding to these surveys and countries then compare themselves against one another other using the results. In this process, views on what counts as literacy, its goals and who literacy learners are, are also shaped. Surveys and their measurement also influence funding and result in funding agreements that are responsive to audits and performance reviews.

However, literacy is not simply an 'autonomous' (Street 1995) skill to be acquired and tested through competency assessment and, if generalised and conceptualised in this way, it can become a vehicle for bringing about the symbolic domination of institutionalised literacies which derive from notions of human capital, economic investment and returns (Becker 1993). When framed by human capital discourses, at the level of the individual, literacy becomes a technology for stratifying human beings as embodied labour power. This framing not only connects literacy to the 
accumulation of knowledge and skills which enable people to increase their productivity and their earnings, but also, within that, it contributes to the stratification of higher prestige literacies with the potential effect of replicating social divisions. Through the sorting and delimitation of individuals, it can also impact on the productivity and wealth of the communities and societies in which they live (Ade-Ojo \& Duckworth 2015).

In many ways this 'economisation' of literacy serves to depoliticise it at the local and individual level. This is consistent with a neoliberal hegemonic view that typically attempts to neutralise politics through a common sense view that economic considerations are sovereign (Davies 2014). In the case of literacy, this involves rupturing its radical emancipatory link to transformation and empowerment. We argue that literacy needs to be positioned within a discourse of transformation which includes the reimagining of the exploration of literacy as a catalyst for hope whereby learners and their communities are positioned positively in relation to possible lifecourse trajectories and other new possibilities that they can imagine for themselves (and for society). Here we are drawing on the thinking of Ernst Bloch who writes powerfully about the connection between hope and agency. For Bloch, hope:

is indestructibly grounded in the human drive for happiness and... has always been too clearly the motor of history... when the will had learnt both through mistakes and in fact through hope as well, and when reality did not stand in too harsh a contradiction to it, (it) reformed a bit of the world; that is an initial fiction was made real. (Bloch 1986 443)

This positive orientation towards the future and to the idea that agency can bring about change in the world inhabited by the individual is viewed by Bloch as an inherent 'drive' in people which is, however, characteristically thwarted by current economic and political conditions. As such:

Hope has to be learned.... It does not just come about automatically but is the produce of experience, failure and resistance to an everyday acceptance of reality.... Hope therefore learns but it also teaches as well as constitutes its own conditions. (Thompson 2013: 7) 
A pedagogy of transformation that embeds hope, care and solidarity can be driven by dialogue with learners about their needs and interests. This connects naturally to broader community learning initiatives in which educators invite learners to take part in a larger community discourse that attempts to solve problems and create alternatives to oppressive situations (Duckworth and Maxwell 2015).

The politics of literacy and its link to learner identity and empowerment is explored in the study from the standpoint of how the learners' everyday lives have been shaped by the lack of and also the development of literacies. The dominant model of 'delivering' literacy education, as previously discussed, has a strong utilitarian function, which 'sorts' learners and distributes literacy in different ways to different social groups; this model of literacy learning reproduces class inequalities and fails to address the impact of power relations in the learners' lives (see Crowther et al. 2006) including the issue of gender inequality (Duckworth 2013). In Bloch's terms, this model of literacy education stifles rather than nurtures hope. This market-driven model often fails to recognise literacy as a tool for personal enlightenment or to mobilise the wider social benefits it can confer with regards to health and well-being. Indeed, literacy education has been shown to enhance confidence, contribute to personal development, promote health, social and political participation and lead to benefits in the public and private domains of learners' lives (Duckworth and Smith, 2018).

\section{Methodology}

The study strove to enact a democratic approach to research. Participants engaged with the project because they had a positive story to tell. The research approach itself became a part of the affirmative practice that helped create the conditions for the transformative learning that participants had often experienced. In that sense, taking part in the research reinforced the positive learning identities that the participants talk about having achieved. Here we were attempting to move away from the kind of 
social critique motivated by 'paternal concern' and intent on the 'diagnosis of incapacity' as identified by Rancière:

In effect the procedures of social critique have as their goal treating the incapable: those who do not know how to see, who do not understand the meaning of what they see, who do not know how to transform acquired knowledge into activist energy. (Rancière 2009: 47)

The methodological approach adopted in this study sought instead to be forwardlooking: to endorse newly established learning identities and to share in a collective imagining of future plans. We strove then to convene research discussions in a safe space, a space moreover that shared some characteristics with critical pedagogical space. As such, the research conversations were typically informal and reciprocal: there was a sharing of stories between the interviewer(s) and the participant. Underpinning this was a sense of research as a social practice (Herndl \& Nahrwold 2000) i.e. not divorced from everyday relations or having any 'mystique' that might in any way make participants feel like 'subjects'. Instead, just as education can be experienced as a socially embedded process that is to a greater or lesser degree conditioned by the social forces and structures that shape our society, so as researchers we were aware of how research can reduce to a limited and convention-ridden exchange between people who do not enjoy an equal social footing. To strive against that we worked to disrupt the assumptions that support that kind of view and underpin that kind of practice.

In that sense, the methodological approach adopted for the study was closely connected to critical pedagogy (Freire 1995, Breunig 2005) and extends some of its underpinning principles. Interviews were framed to foster a sense of equality between participants. This took the form of an initial sharing of stories as we attempted to create an informal atmosphere. As a researcher whose own story has involved transformation through education, one of the research team shared her story with participants. Research conversations (we reject the term 'interviews' because of the 
connotations it carries of an unequal and uni-directional exchange and distribution of power) were also reciprocal and dialogical as stories are exchanged and opinions and feelings shared. Other important features of the research conversations included their informality and the affirmative nature of the conversation. The research positioned itself in such a way as to extend the affirmative regard that we see as underpinning transformative learning experiences. In other words, the conversations sought to affirm the positive learning identities that participants have grown during their studies.

In dissemination, the methodology uses video as a medium for foregrounding participants' voices. One reason for this choice of medium is that the researchers sought to avoid or at least reduce the imposition of our meanings onto their stories. Participants' experience of education frequently involved symbolic violence that sought to position them at the bottom of an existing social order. But symbolic violence does not only occur in educational circles. A critical and reflexive research methodology has to be conscious of the potential for research interactions to visit just the same kind of violence of definition and imposed meanings and of use on participants and their stories. The question we as researchers thought it important to ask ourselves when producing this knowledge and disseminating it was: what meanings were we reinforcing and imposing? Where were we positioning our participants? What impact might dissemination have on their hopes and trajectories? In that sense, the narratives as they were spoken by participants in the videos had the potential to remove the privileged status that researchers are able to assume as the 'brokers' of data and analysis. While edited and framed by the researchers, there is the potential in the use of video to stay true to the affective and situated dimensions of participants' experiences and voices and to limit the research process as being solely or mainly about the creation of cultural capital (Bourdieu and Passeron 1977) within the field of educational research. This field is distinct and exterior to the lifeworlds of the participants and the research might have proceeded methodologically in a way 
that emphasised the distance and distinctness. Instead, our approach was to adopt the approach of research as a social practice centred, an approach furthermore that centred on blurring and breaking down those boundaries. A principle behind our study then was the need for researchers to move away from a methodology in which middle-class observers, whom we would argue might have minimal experience of 'working class life' and consequently 'know very little about working class culture and practices' (see Walkerdine et al. 2001: 83) research, at a distance and in a symbolically violent way, working class lives.

There are resonances here in the way the methodology maps across critical pedagogy in the sense that it is about disrupting 'the present' and insisting instead on 'presence' (Lefebvre 2004). Lefebvre describes the relationship between the present and presence as 'dialectical' (23) and describes 'the present' as:

a skilfully utilised and technicised form of mythification (simplification) (that) resembles the real and presence as a photo of photographed people. Yet, the image, as the present takes care of ideology: it contains it and masks it. The present is a fact and an effect of commerce; while presence situates itself in the poetic: value, creation, situatedness in the world and not only in the relations of exchange. (Lefebvre 2004, 47)

The present here signifies the rhythm of the everyday (or quotidian) which pulls us along and involves us in given meanings in an unquestioning way, which, in short, consolidates existing power relations and inequality. The flipside of this, presence, is a reflexive state of mind and being that steps outside this rhythm and subjects the world to a critical gaze. This criticality is a feature of a transformative learning space in the same way as it can be a room in which a research conversation can take place. The methodology then attempted to produce a shared reflective space in which presence could be experienced.

The posting of video interviews embedded within a project website magnified the interactive potential of the data. The videos became stimulus materials that generated further narratives from an online project audience. At the same time, this publication 
of the data saw the methodological approach affirming further the new learning identities and the new experience of agency of the project participants.

\section{Transformative learning and differential space}

Drawing on the theories about space and time developed by Henri Lefebvre in his book The Production of Space (1991). Lefebvre saw abstract space as 'dominated' and often oppressive and defined it as:

the urban spaces of state regulated neo-capitalism characterised by their commodified exchange value and their tendency to homogenisation (Lefebvre 1991: 49-53)

"Differential space" on the other hand offers a counterpart to abstract space that arises from its contradictions and the inherent possibilities that are constrained within it. Differential space:

... privileges inclusiveness and use value rather than the exchange value of abstract space. It is often transitory space which can arise from the inherent vulnerabilities of abstract space. (Leary-Owhin 2012: 4)

As explained above, literacy within neoliberalism is instrumentalised and mobilised in the service of an imagined national pool of human capital. This economised form of literacy only engages with individuals inasmuch as they are perceived to embody potential economic value. This form of literacy is commodified by the funding arrangements underpinning much further education which attaches an arbitrary 'cost' to the 'doing' and 'delivering' of literacy qualifications.

An alternative view of literacy education connects to the tradition of critical pedagogy that can be traced back to Freire (1995). This alternative provides a setting for the emergence of differential space. Adult literacy classes provide and realise differential space in two significant ways: first, by taking the reductive utilitarian view of education as a starting point and, through an engagement with learners' educational 
biographies, critiquing this; and secondly, by providing an affirmative environment for the development of learners' aspirations and a reorientation to possible lifecourse trajectories in the future. It is this aspect which makes of differential space a landscape in which transformative learning can take place. It is in this sense that transformative learning is an enactment of differential space as 'politicised-democratic space' (LearyOwhin 2015).

Adults with low dominant literacy skills have been largely neglected in explorations of how transformative learning is fostered. Adult Literacy education can often be a critical space to support and empower learners (and indeed tutors against the dominant discourse) to reclaim their agency, no matter what their journey so far. The research data provides evidence for transformation in learners' belief that they could learn to read and write properly to aspiring for and realising her dreams. Working in

a collective was a way for the learners began to see themselves differently as individuals, and to question their positioning in unbalanced power relationships that have marginalised them and their practices of literacy, and acted to change them.

\section{Findings}

\section{Challenging intergenerational poverty and the ripple effect}

Anita

Anita returned to education as a mature student. Regarded as a failure at school because of her dyslexia, she developed a skill set as a parent and in the community. FE harnessed these skills and she began to study to become a social worker.

The teachers at school assumed I was born to fail. Dyslexia was not... I had one teacher at school that sent me for assessment. But it was the early eighties. It had just been identified. So you were thick, you were stupid and if your parents didn't even have any faith in you, you're not going to have any faith in yourself.... I hadn't got a clue what FE meant until someone said it's further education. And I said What does that mean? The progression course before the Access to HE 
course was putting my tie in the water to see if I could so it.... I came to college and started with GCSE, then went onto Access.

Her story shows us how FE can offer opportunities to develop new knowledge and new identities. Importantly, FE provision opens accessible entry opportunities that are calibrated to build confidence. This is an important aspect of the affirmative ethos that transformative learning environments offer.

Anita goes on:

In eighteen months, I'll be a qualified social worker. My tutors are the ones that got me here... They encouraged me. They never once doubted me. They made me grow. Through that, I've been able to inspire my kids. One's at Manchester University... he's in his final year. My daughter wants to go to Oxford to do Medicine. My oldest one has gone into the building trade and is doing fantastically well. He's gone into the management side. He would never have done that but he saw that I could do it. If mum can do it, I can do it. I like to think I have inspired them. I am actually going back, doing something and not just sitting in a cakey shop.

A key theme that emerged from the study in this passage is the notion of the ripple effect of transformative learning. In a sector of education in England that is dominated and governed by metrics (mainly focused on so called success rates: retention $X$ achievement) linked to funding (see for example Smith 2013; Smith and O'Leary 2015) , the notion of the ripple effect is a countermetric: an unmeasured and therefore widely unrecognised social benefit that falls outside a neoliberal purview but nevertheless has a significant positive economic impact beyond the achievement of a qualification by a single individual. Anita's transformation can be described as her following a trajectory that moves away from 'dead-end jobs' towards a career with significant organisational and administrative responsibility and challenging literacy demands. The affirmation of her tutors and the confidence they helped her to 'grow' has led to a realisation of her aspirations with regards to having fulfilling employment. This, in turn, has impacted on her children's aspirations and educational progress. As described above a transformation in the dynamics of her family. The initial barrier that adult education helped Anita to overcome was the constriction of the label of 
being thick / dyslexic that marked her out at school as a failure according to the dominant model of 'autonomous' literacy. Once this constriction had been tackled, the rebirth of hope and the construction of new, positive learning identity leading to a material change in Anita's social positioning inside her family, her community and then in society more widely took place.

\section{Motherhood: different capitals, different literacies}

Anita's narrative illustrates how when mothers' confidence and expertise is repositioned as valued and needed knowledge, they can develop new literacies, advocate for their children and contribute to their literacy progress. Clearly emotional capital is something that Anita needed to draw upon in order to fulfil her role as a mother.

Jade

Jade is a mother who attends adult literacy classes run by a local charitable trust in the north west of England. Being a mum motivates her and she has seen her confidence increase while studying and has learnt new literacies. Now, she has aspirations for her future and is determined to be the best possible role model for her son.

It gives me confidence. It makes me feel better. It makes me feel more like I can go and get what I need to achieve and.. be who I want to be. I just want to be like... someone with a job. Have money. I want to be able to treat my son. I used to get holidays when I was younger and it was exciting and I want to be able to treat my son to stufflike that. At the moment I can't really do that and it's making me feel like I can do it. I can do it. I'm gonna do it... I want to give him the best childhood that he could have and that's by me doing what I want to do as well... I've been through times of depression but I've always tried to stay positive... I've been at the lowest place in life... My son brought me out of it. Children look up to their parents and I want him to look up to me... It's for my son. It's all about him really. What he's had in his life up to now is crap. He deserves a lot more. Kids are innocent and pure and they are the way they are taught...

This passage illustrates the centrality of motherhood as a motivational force for Jade as an adult learner. It is important not to underestimate the affective dimension of the learning experience she is describing. Bourdieu's concept of habitus is useful here. The meanings of habit and habituation that habitus carries within it may be connected 
to established social patterns of being and acting in the world, but they are also bodily, they involve feelings of acceptance and resignation or possibly of resistance and rekindled agency. Jade's account communicated strongly a habitus associated with poverty and unemployment. For her, there was a relationship between these aspects of her life and her mental well-being. The seeming intractability of her circumstances resulted in depression. This feeling of being trapped and locked into a pattern of existence was broken by her involvement in adult education. Jade finds motivation through fond memories of her own childhood, in her hopes for son. These hopes are anchored in the principles of happiness and innocence and she feels it to be her role to provide these for her child.

Emotional capital may be viewed as being essential for opening up possibilities for educational success (Reay 1998, 2000). Emotional capital includes that need to be a good mother, which includes caring for children; this includes the educational care (O'Brien 2007) such as the support offered by Jade and Anita. Reay $(1998,2000)$ suggests that an investment of emotional energy in education by working class mothers depletes their own emotional well-being. However, in Jade and Anita's cases, rather than depletion, we see invigoration: motherhood seems to have acted as a catalyst to the women empowering themselves, returning to education and finding satisfaction in helping their children to succeed.

\section{Marie}

Marie is a staff nurse. She grew up in a large family on an estate in Oldham (where she still lives - through choice). In our conversation with her, she talked about how she went back into education after a negative experience of school. She also talked about the power education has given her and her family to make choices in life. Adult education brought about a turning point in her life when she became 'hooked' on education after starting a course at a local college rather than take up another low paid job opportunity. Through this, adult education became the medium of her 
transformation and through her, brought about a big change in the opportunities and the educational and lifecourse trajectories of her family. As she stated:

I don't care if (my son) stays in education till he's thirty years old. I want him educated because education gives you power and that's what I want my children to have. I want them to be able to make choices. Definitely, I want them to be able to... you know... say, 'Well actually I don't want to do that, I want to do that. And I want to go and live there, I don't want to stay there and live there. And I want to have a car and I want to do this.' Just choices... I want them to be able to go to Costa and get a coffee. Something I could never do... that's what education will give him: choices.

One of the important things in the passage is the emphasis Marie places on the openness of world, the range of opportunities on offer that she wants for her children. This is about positionality in the world and a rekindled sense of agency to act in and on the world. As Bloch states:

Dreams... and possible things circulate inwardly which can perhaps never become outward. Of course, nothing would circulate inwardly either if the outward were completely solid. Outside, however, life is just as little finished as in the ego which is working on this outside. No thing could be altered in accordance with wishes if the world were closed full of fixed, even perfected facts. Instead of these there are simply processes, i.e. dynamic relationships in the Become has not completely triumphed, The Real is process: the latter is the... mediation between present, unfinished past, and, above all: possible future. (Bloch $1986,198)$

There are echoes in the renewed perspective on life and the world in Marie's narrative and Bloch's view of the way dreams and wishes (as expressions of hope) interact with the world. Key in this, is the idea that the world is not fixed and that the Real is an ongoing process of becoming. Transformative learning connects to a sense of becoming which for people who feel trapped in cycles of deprivation and poverty can offer a lifeline.

It's important to note that the positive aspects of transformative learning experiences for Marie were offset by the impact of seeing the world in new critical ways. Marie described having her eyes opened to the systematic inequality of our society and the 
wider world. There is almost a sense of lost innocence in her interview when she describes:

I used to think doctors and police were all good and that people like that never lied. Now I know different..... I used to think people were better than me. But no one's better than anyone: we're all equal.

The unseen literacy at work here is connected to social and cultural capital as defined by Bourdieu but moves beyond that to a newly established 'informed' position within the field of social relations. Through her engagement with learning, Marie has developed a broad-based social literacy - a facility for reading social relations in her workplace but also in society more widely. This social literacy provides Marie with a vantage point from which to understand not only her own position within society but from which to begin to come to grips with the bigger structural forces that shape her life and the lives of others. This social literacy is deeply imbued with criticality as Marie has not only learnt a body of subject knowledge, she has also acquired an understanding of the factors that positioned her where she was before she began her journey.

Acquiring social literacy is about being able to navigate the complexities of different social groups; it's about being able to move without feeling like a fish out of water between different contexts: home, the classroom, the school on parents' evening, the doctor's surgery, the police station with a sense of agency and what Lefebvre (2004) calls 'presence'. We might call it wholeness or confidence but it isn't a façade or a mask, it comes from a deep understanding of the self as subject: our sense of who we are in society.

\section{Nyomi}

Nyomi was studying on a Podiatry degree when we met her in a college in the north east of England. The narratives of participants in this area of the country were all marked by the historical context of the 1984 Miners' Strike. The closure of pits in a large number of villages in the area had severely impacted on job prospects and the 
economic activity in the area. The impact of this was still being felt more than thirty years later.

In common with some other women participants in the project, Nyomi talked about leaving school feeling confident and self-assured and then, losing this confidence through the attrition of unemployment, demanding family circumstances and mental health issues. Nyomi's narrative makes it clear how returning to education, this time with an understanding of her dyslexia, enabled her to change her life. As with Anita Jade and Marie, she talked about the ripple effects of her continued education and the benefits for her family.

I had wanted to be a youth worker. They had pulled quite a lot funding for youth workers at that time. So I then spent the next four years, I would say, unable to find a job, caring for my partner who is on ASA. I kind of spiralled into quite a bad depression. I got pregnant, had my daughter and luckily my daughter gave us a little bit of a boost, so I went and got help for my depression... It was the Health Visitor that spoke to us and tried to get us to get a little bit of motivation and to go back out into the world and try again.

This narrative suggests a tipping point can be reached in people's lives when a combination of external circumstances can seem to create insurmountable obstacles to the realisation of hope. According to the World Health Organisation (WHO), women are more vulnerable to the effects of this.

(W)omen are more likely to suffer from depression, anxiety, psychosomatic systems, eating problems and sexual dysfunction. Violence may also affect their reproductive health. (WHO 2000b: 3 )

Indeed, mental ill health is strongly linked to the prevalence of deprivation and poverty in communities. For Nyomi, her hopes and plans were affected by economic and employment conditions and further affected by family circumstances. Adult education, in the form of an Access to HE course, provided a gateway to renewed hope.

(The course) was hard work, it really was... But it gave me such a sense of belonging. I knew I was doing it for my partner and my daughter. But I also knew that I had to do it for myself. Because I had spent the last four years extremely depressed because of the way my life was panning out. I didn't think... I didn't see myself in education again. And it's hard when you come from living and not having a job and you know that you should be 
working... and nobody employing you... The only thing I could do to give my daughter some kind of life was to do the Access Course. It's been amazing. I opened up. I came off anti-depressants which I'd been on for quite some time. I made friends with people. And I haven't really spoken to a lot of people in years. It really does change your life. It's allowed me to get back out... Within two months I was a completely different person... I've made people proud and I've made myself proud.

Communicated powerfully by the passage is how Nyomi's experience on the Access to HE course helped her reposition herself in relation to the outside world. In a context in which a national, neoliberal grand narrative as espoused by the Thatcher government of the 1980s effectively closed down the aspirations of whole communities in the north east, adult education is seen to offer a space in which individuals can plot a way forward. The importance of the affective aspect of the transformative educational experience is writ large in Nyomi's increased self-esteem and her statement that not only did feel a sense of pride in her achievements but that she had made others proud. This pride can be read as an indicator of the distance travelled on her journey of hope.

\section{The role of teachers in facilitating dialogic care}

According to our research data, teachers in further education play a vital role in creating the social conditions in which transformative learning takes place (Duckworth and Smith, 2016). As a starting point, their practice needs to take account of the negative prior educational experiences of learners who in many cases have been judged and written off by a rigidly linear school system that assesses individuals against a normative, age-staged matrix of 'learning progression'. These teachers understand that in some cases it has taken enormous courage on the part of some would-be adult learners to cross the threshold onto college premises. An initial focus of their work is to create a safe learning environment, establish trust and build confidence.

Judith 
As a teacher, Judith was conscious of the importance of her teaching work in a region with historically high levels of unemployment and job losses.

For me transformational teaching is teaching that makes a difference. Whether it's people enjoying the lesson... or sometimes... people have come in and they've been very quiet and haven't had much confidence. You'll see them five or ten years later and they'll say I'm a primary school teacher now or I'm a social worker or I'm doing my master's degree, I'm doing my PhD. And you think: Wow what a difference!

What's interesting about the description is that Judith does not regard the transformation as something directed by her or even coordinated by her. Instead, the transformative potential is immanent in her practice or rather the impact of her practice on the learners. Judith sees this transformative process as a collective phenomenon and as having social as well as individual origins:

People feel once they get to their twenties or thirties, Oh I didn't stick in at school or I'm not clever enough or I'm never going to do anything. And it only takes one person in a friendship group to go and do something like an Access Course and go on and do well and then their friends want to come on as well.... We have to break the cycle of low aspirations in the north east because we've got whole generations now who don't work...

Judith's understanding of her role is deeply rooted in the location of the college and in the communities the college serves. In this case, her role involves addressing the legacy of the industrial strategies of 1980s Thatcherism when the largescale industries of motor manufacture, coal and steel production had public subsidies withdrawn. Judith identifies some important ingredients in the formation of dialogic caring relationships with the learners. Amongst these, although not specifically named is the respect she has for them as people. Once more the egalitarian nature of transformative teaching and learning comes across powerfully:

We try to get to know the students as people and be part of their journey... A lot of people think they're not academic when actually, they are.... They're so used to thinking of all the things they can't do, we've got to focus on what they can do... By the time they finish they realise that they can do the same as those people they thought were better than them because they had a degree or they are a doctor. I've had people say to me: ... I've learned how to phone up and complain if I'm not happy about something. I've learnt to say, I disagree with that. At the end of the day they are empowered and they have more confidence. 
The emphasis in this is very much on the self-discovery by learners of already-there potential: a process which makes Becoming a realisation of immanence and which unlocks the door to a previously remote and unattainable future. There is a sense then that the teacher's role in the process is one of convening the educational experience and opening up the learning dialogue with individuals. The respect and dignity, the nuanced consideration for individual needs is where the care comes in.

\section{Discussion: The constraints of lacking dominant capital}

These women's stories revealed the impact of dominant capital which included intergenerational poverty and illiteracy on choice/ or lack of choice on their life course. They were brought up in families that were poor and lacked economic capital. There was also constraint as a number of the learners' parents were unable to help them with school work. Due to the fear of being further pathologised a number of learners did not ask for help. Others who did want help were ignored when they asked for it. For them, rather than continuing to resist the label of being 'thick' by asking for help to improve, their resistance shifted to conforming in class, by being silent and thus being further side-lined and ignored by teachers. The learners refused to become part of more humiliation when they had reached the point of realization that their progress/or lack of it did not matter to those who taught them and had made a judgement. As highlighted above, experiencing bullying, labelling and no support mechanisms in the private domain of family and public domain of teachers, many 'hit out' at the system by not bothering going in school. Exams were viewed as a not necessary to their future. On leaving school, they did not have a long term plan about the following year, let alone their future career. Interestingly, rather than the participants being 'anti education' they were instead 'anti school' due to the bullying and symbolic violence they were experiencing across the domains.

School is a site where identities and futures are formed. However, rather than being a site that offers an egalitarian model where everyone is on an equal footing, as shown 
in this research, school is often experienced as a site of marginalisation, social exclusion, and labelling by teachers and peers (often related to family background or estate). At a critical time when the women were becoming aware of themselves and how they fitted into the classroom, self-conscious emotions such as pride, shame and guilt began to emerge. School should be a place where the learners feel comfortable and respected; instead they were anxious, confused and worried for their own wellbeing.

\section{Capitals, class and gender}

The study illustrates that the literacies the women brought to school as children afforded little symbolic value in that it could not be used in class to pass exams. For example, the caring literacy which has been traditionally carried out by girls and women, caring for siblings and their children, seldom enters the public domain and often remains invisible and unrecognised. The working class practices, which were often gendered, were not valued. Wrapped in notions of literacies, were domination and symbolic violence. Oral and written linguistic capabilities were not equally valued in schools, and learners' idiolects (and through them, their identities) were devalued through the hierarchisation of varieties and dialects that positions Standard English as imbued with an intrinsic prestige that masquerades as natural and almost moral in character - rather than as a dialect whose status is rooted in specific historical incident / accident. In this way, the codes and varieties of some social groups are prioritised over the codes of working class and ethnically diverse learners (Bernstein 1971; Labov 1972). This means that learners who were not proficient in the linguistic and 'academic' literacies required in schools were defined as failures or lacking in intelligence simply by virtue of the way they related to and articulated their knowledge of the world. 
Our study explored participants' lives and afforded a comparative exploration of the gendered production of subjectivity in and through education. The school education experience of all the participants was marked by labelling and marginalisation which depleted personal resources of hope and agency. In their experience of adult education however, hope is seen to be renewed and this impacted on their lifecourse trajectories in a way that spreads outwards from the individual to affect families and communities. Our analysis of the learners' life stories moves away from a simplistic notion of individuals 'bettering themselves' - we extend the idea that this is 'linked to their selfhood and social identities' (Luttrell 1997) and rather than viewing working class identities in pathological terms, we see them developing a criticality that repositions them as they are, as working class women, in a new relation to people from other, more privileged and middle class social backgrounds. In Marie's and in Anita's cases (but also in the stories of other participants not covered by this article), this meant bringing a different set of values to their work, and a viewpoint that understood and reached out to people they perceived as coming from a background similar to their own.

Our analysis unpacks these negative ontological assumptions, based on dominant discourses of the middle class, together with what we consider the normative culture, which pathologises gender and class (see Skeggs 1997) and women's and working class experience (see Walkerdine et al. 2001; Skeggs 2004; Lawler 2005; Duckworth 2013).

\section{Dialogic caring and hope}

In the research the learners shared the barriers they faced and the guilt and blame they felt for what they described as being poor, having mental health issues and struggling 
with literacy. This fed into the notion that individuals can rise above the barriers, such as the trauma of labelling experienced by a number of the women in this study. The ideological coupling of choices and opportunities-for-all that was a key theme in New Labour's rhetoric about responsibilities, resurfaced in the notion of the Big Society that was an early policy theme of the Coalition Government (2010-15), has now carried forward in a slightly different form into the agenda of the current conservative government. Theresa May's first speech outside 10 Downing St includes the lines:

When it comes to opportunity, we won't entrench the advantages of the fortunate few. We will do everything we can to help anybody, whatever your background, to go as far as your talents will take you. (Prime Minister's Office 2016)

Here, the meritocratic emphasis of New Labour is transposed into the notion of 'talent': an ideological and mystical quality (reminiscent of IQ) that transcends and therefore makes unnecessary any attempt to address the structural causes of poverty and deprivation and instead places significant emphasis upon an essentialist notion of 'ability'. This in turn implies a condemnation of the lifestyle, culture and choices of the poor and marginalised. We see this in the labelling and pathologising of the women in the study and the impact this has on their notions of choices in the public and private domains that they inhabit and more broadly health and well-being. Culturally sensitive literacy education has the potential to transform students, teachers and researchers to become writers of their own educational stories and, moreover, authors of their own lives. The telling and sharing of the stories, (including through the research), was a way for the women to share what had happened and make the connection with someone who would not judge, but who had similar experiences. In the sharing of these histories the learners began to recognise that what had happened to them at school was not their fault and began to feel a sense of agency in their lives. The research process created a space in which the telling of narratives was experienced as empowering and this can again be linked to the narrative as a capital for resistance against the barriers the women have faced, for example being poor, labelled and stigmatised. Offering a democratic and 'differential' space both in 
the classroom, the community and through research activities for the learners to share their narratives also allowed sharing stories of obstacles and solutions to overcome them. In this context, the narratives in themselves assumed the status of a capital which others drew from to inspire and offer strategies to move themselves and others forward.

\section{Conclusions}

In current neoliberal conditions, educational achievement in schools has been reduced to an institutional quest to improve measurements and metrics in the service of a grand narrative centred on human capital accumulation. This grand narrative views the future primarily in national economic terms. We should not be surprised that these conditions result in the mass labelling of great swathes of the nation's children as failures. After all, up to a third of young people in $2016 \mathrm{did}$ not achieve the national benchmark of 5 GCSEs at $A^{*}-C(R E F)$. But as Bloch identifies, this 'Real' is in process rather than being fixed. All parts of our education system, we might think, should hold to a central purpose of catalysing learners' hope. This research study revealed that adult literacy, and adult education more generally, does give primacy to such a role.

These learners' narratives expose the complexities they experience in their daily lives and how they try to make sense of them from their structural positioning as literacy learners in a society based on inequality of opportunity and choice. Through their educational journeys these women challenge and transform existing hierarchies. As learners they overturn the monopoly on hope that is reified by existing social inequality and the employment and income structures that support this. In this sense, literacy classrooms take on the characteristics of 'differential space' (Lefebvre 1991) as spaces and times in which agency can be rediscovered and an engagement with society on different terms planned for. In this sense, transformative learning is a product of critical pedagogy. Learners described having their eyes opened to 'a whole new world' by returning to education and improving their literacy. One participant, 
Claire, described the power she experienced in simply being listened to and how she longed to return to the classroom in order to experience that empowerment once more. This research illustrates how teachers and researchers and research participants can collaborate to create alternatives for encouraging self-expression and discovery in education. Our vision of education is that more attention needs to be given to marginalised individuals and populations in the context of curricular innovations that both enhance and promote literacy development and personal self-esteem.

The study exposed how teachers, even when constrained by performative curricula, open up a space for critical reflection and dialogue which facilitates learners to challenge notions of what literacies are. It was this move from a competence-based model to a holistic approach (see Morrish et al. 2002) and care (see Feeley 2007, Duckworth 2013, 14) which allowed us to fully explore the learners' motivations and barriers. Dialogic care was an integral aspect of the methodological approach.

Often transformative education is hidden from view because the impact falls outside the metrics that drive further education policy and that underpin funding. It is often not measured by blunt assessment. We argue for a move towards a transformative tool for Adult Education and literacy programmes: flexible, participatory and appropriate to improve their life skills, reproductive health and livelihood; which strengthen their participation and leadership in the public sphere; and ensure gender justice through equal access to Adult Education and Lifelong Learning processes. 


\section{References}

Ade-Ojo, G. \& Duckworth, V. 2016. Of cultural dissonance: the UK's adult literacy policies and the creation of democratic learning spaces. International Journal of Lifelong Education.

http://www.tandfonline.com/doi/abs/10.1080/02601370.2016.1250232

Baudrillard, J. 1994. Simulacra and Simulation, Ann Arbor: University of Michigan Press.

Becker, Gary, S. 1993. Human Capital, A theoretical and empirical analysis with special reference to education. London: University of Chicago Press.

Bloch, Ernst. 1986. The Principle of Hope. Volume 1. Cambridge Mass.: MIT Press.

Breunig, M. 2005. Turning Experiential Education and Critical Pedagogy Theory into Praxis, Journal of Experiential Education. 28 (2) 106-122.

Bourdieu, P. \& Passeron, J. 1977. Reproduction in Education, Society and Culture. London: Sage.

Davies, W. 2014. The Limits of Neoliberalism. Sage: London.

Duckworth, V. 2013. Learning Trajectories, Violence and Empowerment amongst Adult Basic Skills Learners. Abingdon, Oxon: Routledge.

Duckworth, V. (2014) Literacy and Transformation, in Duckworth, V. and Ade-Ojo, G. (eds.) Landscapes of Specific Literacies in Contemporary Society: Exploring a social model of literacy. Monograph: Routledge Research in Education: London pp 27 - 46

Duckworth, V. \& Smith, R. 2016. Further education in England - Transforming lives and communities: Interim Report. UCU http://transforminglives.web.ucu.org.uk/files/2017/03/Transforming lives IWD Mar 
17_12pp.pdf (accessed 30.07.17)

Duckworth, V. and Smith, R. 2018. Transformative Learning in English Further

Education, in Borg, C; Mayo, P and Sultana, R (ed) Skills for sustainable Human Development of the International Handbook on Vocational Education and Training for changing the world of work. Springer

Duckworth, V. and Maxwell, B. (2015) Extending the mentor role in initial teacher education: Embracing social justice, International Journal of Mentoring and Coaching in Education, 4 (1) 4-20

Freire, P. 1995. The Pedagogy of the Oppressed. New York: Continuum.

Herndl, C. \& Nahrwold, C. 2000. Research as Social Practice. Written Communication: $17(2), 258-296$.

Illeris, K. 2013. Transformative Learning and Identity. London: Routledge.

Labov, W. 1972. . Sociolinguistic Patterns. Philadelphia: University of Pennsylvania.

Leary-Owhin, M. 2015. A Fresh Look at Lefebvre's Spatial Triad and Differential Space: A Central Place in Planning Theory. Updated working draft revision of a paper given at the 2nd Planning Theory Conference, University of the West of England. 21-22 June 2012. Accessed September 17, 16.

https://www.academia.edu/17161563/A Fresh Look at Lefebvre s Spatial Triad a nd Differential Space A Central Place in Planning Theory.

Lefebvre, H. 1991. The Production of Space. Oxford: Blackwell.

Lefebvre, H. 2004. Rhythmanalysis: Space, Time and Everyday Life. New York:

Continuum.

Mezirow, J. and associates. 2000. Fostering Critical Reflection: A Guide to Transformative and Emancipatory Learning. Mahwah: Jossey-Bass. 
Prime Minister's Office. 2016. Statement from the new Prime Minister Theresa May.

https://www.gov.uk/government/speeches/statement-from-the-new-prime-minister-

theresa-may. Accessed 28.07.17.

Pant-Robinson, A. 2016. Promoting Health and Literacy for Women's

Empowerment. UNESCO Institute for Lifelong Learning (UIL).

http://uil.unesco.org/literacy-and-basic-skills/focus-women/investigating-

relationship-between-literacy-health-and-womens. Accessed 30.07.17

Rancière, J. 2009. The Emancipated Spectator. London: Verso.

Reay, D. 1998. 'Always knowing' and 'never being sure': institutional and familial habituses and higher education choice, Journal of Education Policy, 13(4), 519-529.

Reay, D. 2000. "Dim Dross": marginalised women both inside and outside the Academy. Women's Studies International Forum 23(1), 13-21.

Skeggs, B. (1997). Formations of class \& gender. London: Sage.

Smith, R. 2015. College re-culturing, marketisation and knowledge: the meaning of incorporation, Journal of Educational Administration and History, 47:1, 18-39.

Smith, R. \& O'Leary, M. 2013. New Public Management in an age of austerity: knowledge and experience in further education, Journal of Educational Administration and History, 45:3, 244-266.

Street, B. 1995. Social Literacies: Critical Approaches to Literacy in Development, Ethnography and Education. London: Longman.

Walkerdine, V., Lucey, H., \& Melody, J. 2001. Growing up girl: Psychosocial 
explorations of gender and class. London: Palgrave. 